P-ISSN: 2664-3685

E-ISSN: $2664-3693$

www.paediatricjournal.com IJPG 2018; 1(2): 06-08

Received: 10-05-2018

Accepted: 12-06-2018

Dr. Upendra Rao

Department of Paediatrics, Govt. Medical College \&

Hospital, Balasore, Odisha, India
Corresponding Author: Dr. Upendra Rao Department of Paediatrics, Govt. Medical College \& Hospital, Balasore, Odisha, India

\section{Evaluation of lead poisoning in children age ranged 2- 10 years old}

\section{Dr. Upendra Rao}

DOI: https://doi.org/10.33545/26643685.2018.v1.i2a.11

\begin{abstract}
Background: Lead poisoning is one of the major environmental diseases among children in developing countries. The present study was conducted to assess lead level in children.

Materials \& Methods: The present study was conducted on 156 cases of lead poisoning of both genders of age ranged 2-10 years. In all children, symptom suggestive of lead poisoning like pallor, unexplained fatigue, abdominal pain, constipation or anorexia, deteriorating school performance, and recently acquired irritability or hyperactive behaviour was recorded. Reasons for lead poisoning were recorded.

Results: Out of 156 patients, boys were 80 and girls were 76. Age group 2-4 years had 26 children, 4-6 years had 67, 6-8 years had 35 and 8-10 years had 28 children. Possible reasons seen in children were thumb sucking (26), use of colored toys (68), pets (34), absence of hand washing (65), use of herbal medications (35) and pencil biting (82). The difference was significant $(P<0.05)$.

Conclusion: Lead poisoning in children is a serious issue. The possible reasons found was thumb sucking, use of colored toys, pets, absence of hand washing, use of herbal medications and pencil biting.
\end{abstract}

Keywords: Children, Lead poisoning, pencil

\section{Introduction}

Lead poisoning is one of the major environmental diseases among children in developing countries ${ }^{[1]}$. A recent controversy involving a popular brand of noodles in India recently led to increased awareness about the potentials of lead toxicity. Exposure to even extremely small amounts of lead can have long-term and slowly accumulating deleterious effects in children ${ }^{[2]}$.

State and local childhood blood lead surveillance systems retain the results of blood lead tests of children reported to state health departments by private laboratories, as well as state and local government laboratories. The reporting criteria of BLLs from the laboratories to the state are set by each state and vary across jurisdictions ${ }^{[3]}$.

Primary prevention, reducing or eliminating the myriad sources of lead in the environment of children before exposure occurs, is the most reliable and cost-effective measure to protect children from lead toxicity ${ }^{[4]}$. Very high blood lead concentrations (eg, $>100 \mu \mathrm{g} / \mathrm{dL}$ ) can cause significant overt symptoms, such as protracted vomiting and encephalopathy, and even death. Low-level lead exposure, even at blood lead concentrations below $5 \mu \mathrm{g} / \mathrm{dL}$ (50 ppb), is a causal risk factor for diminished intellectual and academic abilities, higher rates of neurobehavioral disorders such as hyperactivity and attention deficits, and lower birth weight in children ${ }^{[5]}$. The present study was conducted to assess lead level in children.

\section{Materials \& Methods}

The present study was conducted in the department of pediatrics. It comprised of 156 cases of lead poisoning of both genders of age ranged 2-10 years. The study protocol was approved from institutional ethical committee and written consent was obtained from parents of all children.

Data related to children such as name, age, gender etc. was recorded. In all children, symptom suggestive of lead poisoning like pallor, unexplained fatigue, abdominal pain, constipation or anorexia, deteriorating school performance, and recently acquired irritability or hyperactive behaviour was recorded. The blood sample was obtained under sterile conditions. Reasons for lead poisoning were recorded. Results were tabulated and subjected to statistical analysis. $\mathrm{P}$ valve less than 0.05 as considered significant. 


\section{Results}

Table 1: Distribution of patients

\begin{tabular}{|c|c|c|}
\hline & Total- 156 & \\
\hline Gender & Boys & Girls \\
\hline Number & 80 & 76 \\
\hline
\end{tabular}

Table I shows that out of 156 patients, boys were 80 and girls were 76 .

Table 2: Age wise distribution

\begin{tabular}{|c|c|c|}
\hline Age group (Years) & Number & \multirow{2}{*}{ P value } \\
\hline $2-4$ & 26 & \multirow{2}{*}{0.02} \\
\hline $4-6$ & 67 & \\
\hline $6-8$ & 35 & \\
\hline $8-10$ & 28 & \\
\hline
\end{tabular}

Table II shows that age group 2-4 years had 26 children, 4-6 years had 67, 6-8 years had 35 and 8-10 years had 28 children.

Table 3: Possible reasons for lead poisoning

\begin{tabular}{|c|c|c|}
\hline Reasons & Number & P value \\
\hline Thumb sucking & 26 & \\
\hline Use of colored toys & 68 & \\
\hline Pets & 34 & \multirow{2}{*}{0.04} \\
\cline { 1 - 2 } Absence of hand washing & 65 & \\
\hline Use of herbal medications & 35 & \\
\hline Pencil biting & 82 & \\
\hline
\end{tabular}

Table III, graph I shows that possible reasons seen in children were thumb sucking (26), use of colored toys (68), pets (34), absence of hand washing (65), use of herbal medications (35) and pencil biting (82). The difference was significant $(\mathrm{P}<0.05)$.

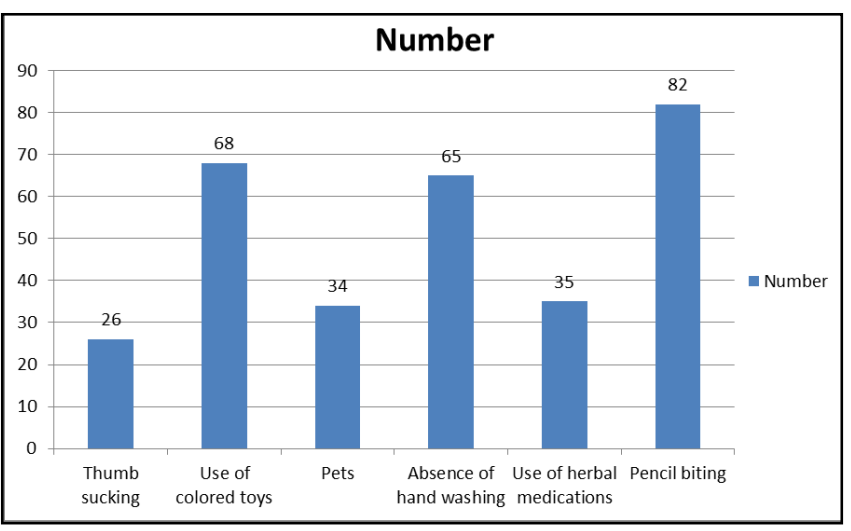

Graph 2: Possible reasons for lead poisoning

\section{Discussion}

Before ACCLPP's recommendation in May 2012, the level for which public health intervention was warranted for children aged $<6$ years was $\geq 10 \mu \mathrm{g} / \mathrm{dL}$. Since then, the reference level has shifted to $\geq 5 \mu \mathrm{g} / \mathrm{dL}$. For this report, elevated blood lead levels are defined as confirmed BLLs $\geq 10 \mu \mathrm{g} / \mathrm{dL}$. Data on children with BLLs $\geq 5 \mu \mathrm{g} / \mathrm{dL}$ also are reported because the change to a reference value did not occur until mid-2012 and federal funding from CDC to state and local health departments ended in September 2012 and resumed in late $2014^{[6]}$.

Studies suggest that the population groups at greatest risk of exposure are young children and workers involved with construction, mining, and manufacturing. This may be due to greater gut absorption of lead in infants and young children than in adults ${ }^{[7]}$. The present study was conducted to assess lead level in children.

In present study, out of 156 patients, boys were 80 and girls were 76 . We observed that age group 2-4 years had 26 children, 4-6 years had 67, 6-8 years had 35 and 8-10 years had 28 children. Needleman et al ${ }^{[8]}$ in their study determined the prevalence and correlates of elevated blood lead level in children (6-144 months). A total of 260 children were enrolled. The prevalence of elevated blood lead level was $44.2 \%$, seen mostly in children below 5 years of age. Old and deteriorating wall paints at home was found to be significantly associated with elevated levels.

We found that possible reasons seen in children were thumb sucking (26), use of colored toys (68), pets (34), absence of hand washing (65), use of herbal medications (35) and pencil biting (82). Reducing lead exposure from residential lead hazards, industrial sources, contaminated foods or water, and other consumer products is an effective way to prevent or control childhood lead exposure. Lead poisoning prevention education directed at hand-washing or dust control fails to reduce children's blood lead concentrations. However, pediatricians and parents should be aware of measures to reduce the toxic effects of lead on children, including the promulgation of regulations to screen or test older housing units for lead hazards ${ }^{[9]}$.

The primary sources of lead in water, which can be dissolved or particulate, consist of lead service lines, lead solder, and brass fittings that contain high concentrations of lead. Plumbing installed before 1986, the year a federal ban was issued on using lead pipe and lead solder and a maximum lead content of $8 \%$ by weight for brass plumbing was established, is more likely to contain higher concentrations of lead. Lead services lines that are being replaced, are undergoing maintenance, or are damaged can release particles of lead that can be ingested ${ }^{[10]}$.

\section{Conclusion}

Lead poisoning in children is a serious issue. The possible reasons found was thumb sucking, use of colored toys, pets, absence of hand washing, use of herbal medications and pencil biting.

\section{References}

1. Schwartz J. Low-level lead exposure and children's IQ: a meta-analysis and search for a threshold. Environ Res. 1994; 65:42-55.

2. Canfield RL, Henderson CR, Cory-Slechta DA, Cox C, Jusko TA, Lanphear BP. Intellectual impairment in children with blood lead concentrations below 10 microg per decilitre. N Engl J Med. 2003; 348:1517-26.

3. Amitai Y, Brown MJ, Graef JW, Cosgrove E. Residential deleading: effects on the blood lead levels of lead-poisoned children. Pediatrics. 1991; 88(5):893897.

4. Clark S, Grote J, Wilson $\mathrm{J}$ et al. Occurrence and determinants of increases in blood lead levels in children shortly after lead hazard control activities. Environ Res. 2004; 96(2):196-205

5. Spanier AJ, Wilson S, Ho M, Hornung R, Lanphear BP. The contribution of housing renovation to children's blood lead levels: a cohort study. Environ Health. 2013; 12:72.

6. Shannon M, Graef JW. Lead intoxication from lead- 
contaminated water used to reconstitute infant formula. Clin Pediatr (Phila). 1989; 28(8):380-382.

7. Roscoe RJ, Gittleman JL, Deddens JA, Petersen MR, Halperin WE. Blood lead levels among children of lead-exposed workers: a meta-analysis. Am J Ind Med. 1999; 36(4):475-481.

8. Needleman HL, Gatsonis CA. Low-level lead exposure and the IQ of children: A meta-analysis of modern studies. JAMA. 1990; 263:673-8.

9. Farfel MR, Rohde C, Lees PSJ, Rooney B, Bannon DL, Derbyshire W. Lead-Based Paint Abatement and Repair and Maintenance Study in Baltimore: Findings Based on Two Years of Follow-Up. Washington, DC: US Environmental Protection Agency, 1998.

10. Liu J, Ai Y, McCauley L, Pinto-Martin J, Yan C, Shen $\mathrm{X}$ et al. Blood lead levels and associated sociodemographic factors among preschool children in the south eastern region of China. Paediatr Perinat Epidemiol. 2012; 26:61-9. 